\title{
Mechanical Response of PbSSe, PbSTe Ternary and PbSnSTe Quaternary Alloys at High Pressure
}

\author{
Mazin Sh. Othman \\ Department of General Science, Faculty of Education, Soran University, \\ Kurdistan Region - F.R. Iraq
}

\begin{abstract}
Property of the semiconductors under high pressure is investigated by the density functional theory and paralleled to the foretelling of the linear elasticity theory. In addition, ternary alloys of $\mathrm{PbS}_{\mathrm{x}} \mathrm{Se}_{1-\mathrm{x}}$ and $\mathrm{PbS}_{\mathrm{x}} \mathrm{Te}_{1-\mathrm{x}}$ lattice matching $\mathrm{PbS}$ substrate for $\mathbf{x}=0.5$ compositions are studied. Furthermore, quaternary alloys $\mathrm{Pb}_{\mathrm{x}} \mathrm{Sn}_{1-\mathrm{x}} \mathrm{S}_{\mathrm{y}} \mathrm{Te}_{1-\mathrm{y}}$ lattice matching PbS substrate for $\mathrm{x}$ and $\mathrm{y}=\mathbf{0 . 5}$ compositions are studied. The six independent elastic parameters $(C i j)$ are also calculated. Meanwhile, the results data are analyzed in high pressure. The mechanical response of all alloys to pressures 0 , 50 and 100 kbar increases progress to decrease in $(C i j)$ in separate rates. The rapprochement between the calculated results and the available published data for these alloys demonstrate that they had worthy accordance at zero pressure and the results at high pressure may be required as an acceptable reference.
\end{abstract}

Index Terms-Alloys, High pressure, Mechanical response, PbSSe, PbSTe, PbSnSTe.

\section{INTRODUCTION}

The study of the mechanical response of materials is significant in both the fundamental physics and high-pressure technique. The selection of the mechanical response under pressure is extremely risky by theoretical simulations. A strong connection exists between these properties with shear rigidity of materials and with their elastic moduli (Suresh Babu, Vijayan and Devanathan, 2004). The technical significance of the $\mathrm{PbS}$ and $\mathrm{PbSSe}$ groups of semiconductor compounds and alloys as detectors of infrared radiation has been a powerful parallel stimulus.

They are chiefly used in infrared lasers in fiber optics, including thermoelectric materials, in solar energy panels, and in window coating (Othman, Mishjil and Habubi, 2012; Othman, et al., 2019). Their narrow fundamental energy band gap is one of their effective properties (Gopal, et al., 2015). Thus, IV-VI semiconductor alloys are worthwhile in optoelectronic devices such as lasers (McCann, 2006; Hutter, et al., 2014). Countless studies, theoretically and

ARO-The Scientific Journal of Koya University

Vol. VIII, No.2 (2020), Article ID: ARO.10681, 5 pages DOI:10.14500/aro.10681

Received: 21 May 2020; Accepted: 12 August 2020

Regular research paper: Published: 03 September 2020

Corresponding author's e-mail: mazin.othman@soran.edu.iq Copyright (C) 2020 Mazin Sh. Othman. This is an open-access article distributed under the Creative Commons Attribution License. experimentally, related to these materials are available (Lebedev and Sluchinskaya, 1994) and explored the samples of $\mathrm{PbS}_{\mathrm{x}} \mathrm{Se}_{\mathrm{y}} \mathrm{Te}_{1-\mathrm{x}-\mathrm{y}}$ quaternary solid solutions at low temperatures using electrical and X-ray methods (Weyand, 2007); ab initio study of cubic alloys (Kacimi, et al., 2008); structure, electronic, and optical properties of $\mathrm{PbS}_{1-\mathrm{x}} \mathrm{Se}_{\mathrm{x}}$ (Labidi, et al., 2011); and simulation mechanical properties of $\mathrm{PbS}_{0.5} \mathrm{Se}_{0.5}$ under pressure (Othman, 2013). The existent study was performed to highlight on the studies which are done in the future by the specialists to deliver and examine these alloys in laboratories. It assists them determine the change in amounts of additives in alloys, the friendship of theoretical studies with experiments and other theoretical works.

The mechanical performance of $\mathrm{PbS}_{x} \mathrm{Se}_{1-\mathrm{x}}$ and $\mathrm{PbS}_{\mathrm{x}} \mathrm{Te}_{1-\mathrm{x}}$ ternary, $\mathrm{Pb}_{\mathrm{x}} \mathrm{Sn}_{1-\mathrm{x}} \mathrm{S}_{\mathrm{y}} \mathrm{Te}_{1-\mathrm{y}}$ quaternary alloys high pressure for $\mathrm{x}$ and $\mathrm{y}=0.5$ compositions changes under pressure, which in a straight line impact a variety of applications of $\mathrm{PbS}$ compound devices under diverse working circumstances. Concerning various application circumstances, the mechanical performance of these alloys at 0,50 , and 100 kbar is considered using density functional theory (DFT) calculations in the current work.

\section{Materials AND Methods}

Cambridge Serial Total Energy Package (CASTEP) program is used to analyze the data (Segall, et al., 2002). Kohn-Sam formation is used to complete the calculation (McGinty, et al, 2009). Using DFT to the exchangecorrelation contribution is explained within the local density approximation (LDA). A cubic unit cell is centered with atoms $(\mathrm{S} / \mathrm{Se})$ and $(\mathrm{S} / \mathrm{Te})$ of $\mathrm{PbS}_{\mathrm{x}} \mathrm{Se}_{1-\mathrm{x}}$ and $\mathrm{PbS}_{\mathrm{x}} \mathrm{Te}_{1-\mathrm{x}}$ ternary alloys and set up with atoms $(\mathrm{Pb} / \mathrm{Sn})$ and $(\mathrm{S} / \mathrm{Te})$ of $\mathrm{Pb}_{\mathrm{x}} \mathrm{Sn}_{1-\mathrm{x}} \mathrm{S}_{\mathrm{y}} \mathrm{Te}_{1-\mathrm{y}}$ quaternary alloys for $\mathrm{x}$ and $\mathrm{y}$ compositions. It is indicated that quaternary alloys have cubic symmetry in all of the calculations for all the five systems to preserve constancy and easiness. Cubic unit cell was taken for $\mathrm{x}$ and $\mathrm{y}$ and we substituted atoms to achieve the coveted concentrations. The completion of the first step of geometry optimization is done for $\mathrm{PbS}_{\mathrm{x}} \mathrm{Se}_{1-\mathrm{x}}$ and $\mathrm{PbS}_{\mathrm{x}} \mathrm{Te}_{1-\mathrm{x}}$ ternary alloys and $\mathrm{Pb}_{\mathrm{x}} \mathrm{Sn}_{1-\mathrm{x}} \mathrm{S}_{\mathrm{y}} \mathrm{Te}_{1-\mathrm{y}}$ quaternary alloys for $\mathrm{x}$ and $\mathrm{y}=0$ at constant temperature with symmetry P1. Fig. 1 displays the graph of improvement steps provided merely for $\mathrm{Pb}_{\mathrm{x}} \mathrm{Sn}_{1-\mathrm{x}} \mathrm{S}_{\mathrm{y}} \mathrm{Te}_{1-\mathrm{y}}$ quaternary alloys to gain gap in journal. The calculation is perfected using Kohn- 
Sam formation, which used DFT to the exchange-correlation contribution. It is determined by LDA. The wave functions have been extended in the plane waves up to a kinetic energy cutoff of $890 \mathrm{eV}$. Atomic positions are adjusted with a density mixing scheme (Othman, Kasap and Korozlu, 2010a) including the conjugate gradient (CG) process for values minimization (Ahmed, et al., 2008). Under dissimilar pressure, the Monkhorst-Pack scheme with regular integration points is put in an application (Milman, et al., 2010; Sedighi, et al., 2020).

\section{RESULTS AND DiSCUSSION}

Below are the elements which acted the external forces in mechanical performance. They are also called stress. In addition, whereas the body is in equilibrium, the external stress has to be perfectly well adjusted by internal forces. Overall, the stress is a second rank tensor with nine following elements (Othman, Kasap and Korozlu, 2010b; Othman, 2016; Dar, et al., 2017):

$$
\tau_{i j}=\left|\begin{array}{l}
\tau_{11} \tau_{12} \tau_{13} \\
\tau_{21} \tau_{22} \tau_{23} \\
\tau_{31} \tau_{32} \tau_{33}
\end{array}\right|
$$

Using the so-called virile expression, the internal stress is possibly achieved in an atomistic computation

$$
\tau=\frac{1}{I}\left\{\sum_{i=1}^{N} m_{i}\left(v_{i} v_{i}^{T}\right)+\left(\sum_{i>j} r_{i j} F_{i j}^{T}\right)\right.
$$

where index indicates particles 1 by means of $N, \eta_{i}$, vi, and $F_{i}$ symbolize the mass, velocity, and force working on character $i, v$ means the arrangement volume. Application of a stress of body brings about a modification in the relative positions of particles in the body, directed quantitatively by way of the strain tensor:

$$
\eta_{i j}=\left|\begin{array}{l}
\eta_{11} \eta_{12} \eta_{13} \\
\eta_{21} \eta_{22} \eta_{23} \\
\eta_{31} \eta_{32} \eta_{33}
\end{array}\right|
$$

parallelepiped (e.g., a periodic simulation cell) categorized in some references, stated by the three column vectors $a_{0}, b_{0}$, and $c_{0}$, and by the vectors $a, b$, and $c$ in the distorted state, the strain tensor is expressed by:

$$
\eta=\frac{1}{2}\left[\left(\mathrm{P}_{0}^{T}\right)^{-1} \mathrm{KP}_{0}^{-1}-1\right]
$$

where $P_{0}$ points to the matrix formed from the three column vectors $a_{0}, b_{0}$, and $c_{0}$. $P$ signifies the corresponding matrix formed from $a, b$, and $c$. $T$ indicates the matrix interpret. $K$ means the metric tensor $P^{\mathrm{T}} \mathcal{P}$. The elastic hardness coefficients concerning the various components of stress and strain are defined by:

$$
C_{\text {imnk }} \frac{\partial \tau_{i m}}{\partial \eta_{n k}}\left|\frac{1}{\dot{y}} \frac{\partial^{2} A}{\partial \eta_{l m} \partial \eta_{n k}}\right|_{T, \eta_{l m} \eta_{n k}}
$$

where $A$ stands for the Helmholtz which releases energy. For small deformations, the affiliation between the stresses and strains may be stated basing on a popularized:

$$
\begin{gathered}
\tau_{l m}=C_{\text {lmnk }} \eta_{n k} \\
\eta_{l m}=S_{\text {imnk }} \tau_{n k}
\end{gathered}
$$

where $S_{\text {lmnk }}$ denotes the compliance components. Note that in both Equations (6) and (7), the summation convention is indicated. For example, $\eta_{21}$ is provided in full as:

$$
\begin{aligned}
\tau_{21}= & C_{2111} \eta_{11}+C_{2112} \eta_{12}+C_{2113} \eta_{13}+C_{2121} \eta_{21}+C_{2122} \eta_{22} \\
& +C_{2123} \eta_{23}+C_{2131} \eta_{31}+C_{2132} \eta_{32}+C_{2133} \eta_{33}
\end{aligned}
$$

The popularized Hooke's law is consequently often written as:

$$
\tau_{i}=C_{i j} \eta_{j}
$$

The $6 \times 6$ hardness matrix $C$ is also corresponding. Therefore, 21 coefficients are needed to completely expound the stress-strain properties of an arbitrary substance. Moreover, $C$ is a tensor, since it does not abide by the needed transformation rules.

$\rho$ and $\varsigma$ refer to the Lamé coefficients. For the isotropic case, expressions are used for the Young modulus $Y$ and bulk modulus $B$ which are provided as follows (Jandow, et al., 2019):

$$
\begin{aligned}
Y & =\rho\left(\frac{3 \varsigma+2 \rho}{\varsigma+\rho}\right) \\
& =\varsigma+-
\end{aligned}
$$

The finite strain method is applied to calculate the elastic constants, in which the ground-state structure is forced to unusual great effort in accordance with symmetry-dependent

TABLE I

Equilibrium Lattice Parameters $(\alpha)$, Bulk Modulus (GPa), and Band Gap Energy ( $\left.E_{\mathrm{G}}\right)$ OF All Alloys

\begin{tabular}{lccc}
\hline \hline Materials & Pressure $($ kbar $)$ & $\alpha_{0}(\AA)$ & $E g(\mathrm{eV})$ \\
\hline $\mathrm{PbS}(\mathrm{Se})$ & 0 & 6.041 & 0.263 \\
& 50 & 5.987 & 0.378 \\
& 100 & 5.746 & 0.506 \\
$\mathrm{PbS}(\mathrm{Te})$ & 0 & 6.301 & 0.194 \\
& 50 & 6.142 & 0.273 \\
& 100 & 6.009 & 0.299 \\
$\mathrm{PbSnSTe}$ & 0 & 5.840 & 0.642 \\
& 50 & 5.753 & 0.691 \\
& 100 & 5.701 & 0.753 \\
\hline \hline
\end{tabular}

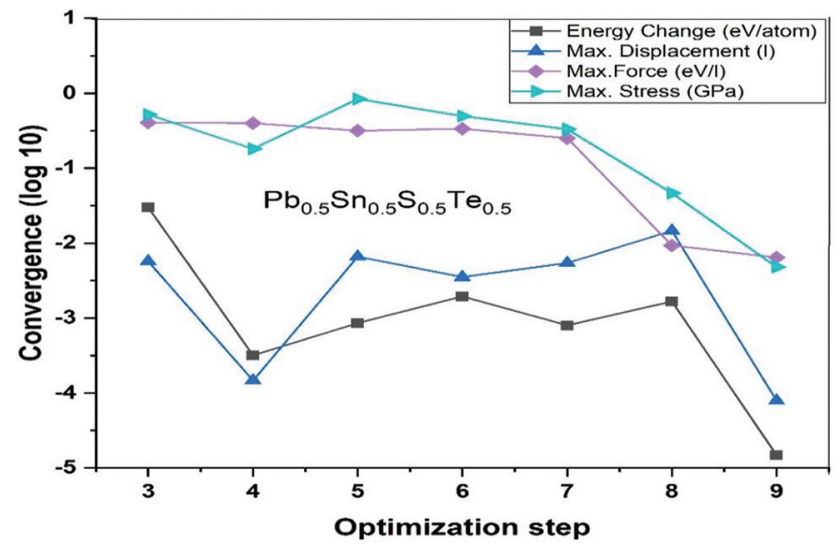

Fig. 1. The optimization step convergence of $\mathrm{Pb}_{\mathrm{x}} \mathrm{Sn}_{1-\mathrm{x}} \mathrm{S}_{\mathrm{y}} \mathrm{Te}_{1-\mathrm{y}}$. 

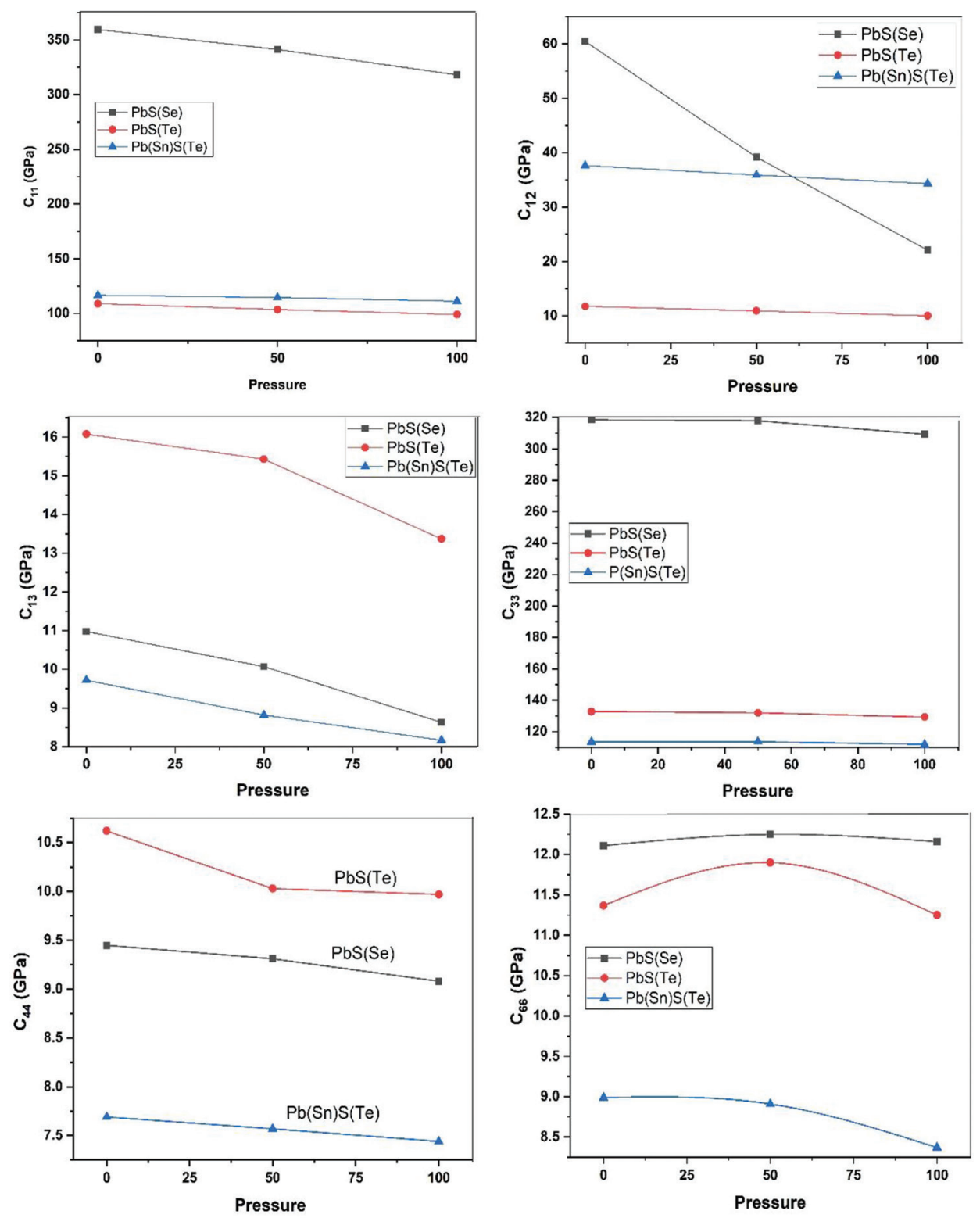

Fig. 2. Elastic constants of $C_{11}, C_{12}, C_{13}, C_{33}, C_{44}$, and $C_{66}$ of $\mathrm{PbS}_{\mathrm{x}} \mathrm{Se}_{1-\mathrm{x}}$ and $\mathrm{PbS}_{\mathrm{x}} \mathrm{Te}_{1-\mathrm{x}}$ ternary and $\mathrm{Pb}_{\mathrm{x}} \mathrm{Sn}_{1-\mathrm{x}} \mathrm{S}_{\mathrm{y}} \mathrm{Te}_{1-\mathrm{y}}$ quaternary alloys.

strain patterns with changing amplitudes and a subsequent calculation of the stress tensor after optimization of the internal structure parameters. In addition to that, the bulk modulus $B$ is calculated from the elastic constants. Then, Young's modulus is computed from these values.

Table I displays lattice parameter of $\mathrm{PbS}_{x} \mathrm{Se}_{1-x}$ and $\mathrm{PbS}_{\mathrm{x}} \mathrm{Te}_{1-\mathrm{x}}$ ternary and $\mathrm{Pb}_{\mathrm{x}} \mathrm{Sn}_{1-\mathrm{x}} \mathrm{S}_{\mathrm{y}} \mathrm{Te}_{1-\mathrm{y}}$ quaternary alloys for $\mathrm{x}$ and $\mathrm{y}$ compositions with increasing pressure $(P=0.50$, and $100 \mathrm{kbar})$. These lattice parameters decline, as pressure rises. Moreover, whereas forbidden band gap energy goes up because of the pressure. For further information, as pressure increases, many of materials often get metallic. Furthermore, the atoms come closer, and the lattice parameter goes down. Thus, all modulus enlarge. Eventually, the referred materials get metallic than the pressure decreases (Koch, et al., 2005). A connection is provided between the mechanical characteristic of crystals by the elastic parameters of materials, which display information in terms of the nature of the forces operating in materials. Particularly, they give information about the materials' constancy and rigidity. Accurate ways and means must be applied to their first principle calculation. Since these forces and the elastic parameters are considered as the functions of the first-order and second-order derivatives of the potentials, the calculation demonstrates more detail about the accuracy of forces in materials. The second-order elastic parameters $(C i j)$ are done by means of the "volumeconserving" proses (Sanati, et al., 2013) and the findings are indicated in Table II. For a stable tetragonal structure, the six independent elastic constants $C i j$ should gratify the BornHuang for constancy (Mouhat and Coudert, 2014),

$$
\begin{gathered}
C_{11}>0, C_{33}>0, C_{44}>0, C_{66}>0,\left(C_{11}-C_{12}\right)>0, \\
\left(C_{11}+C_{33}-2 C_{13}\right)>0, \\
\left\{2\left(C_{11}+C_{12}\right)+C_{33}+4 C_{13}\right\}>0
\end{gathered}
$$

Table II indicates that elastic constants follow the stability conditions for $\mathrm{PbS}_{\mathrm{x}} \mathrm{Se}_{1-\mathrm{x}}$ and $\mathrm{PbS}_{\mathrm{x}} \mathrm{Te}_{1-\mathrm{x}}$ ternary and 
TABLE II

Elastic Parameters Moduli of these Alloys Under High Pressure

\begin{tabular}{lccccccccc}
\hline \hline Materials & Pressure $(\mathrm{kbar})$ & $C_{11}(\mathrm{GPa})$ & $C_{12}(\mathrm{GPa})$ & $C_{13}(\mathrm{GPa})$ & $C_{33}(\mathrm{GPa})$ & $C_{44}(\mathrm{GPa})$ & $C_{66}(\mathrm{GPa})$ & Bulk modulus $(\mathrm{GPa})$ & Young's modulus $(\mathrm{GPa}) \times 10^{-2}$ \\
\hline $\mathrm{PbS}(\mathrm{Se})$ & 0 & 359.43 & 60.47 & 10.98 & 318.43 & 9.45 & 12.11 & 51.42 & 3.708 \\
& 50 & 341.26 & 39.18 & 10.07 & 317.92 & 9.31 & 12.25 & 43.27 & 3.594 \\
& 100 & 317.92 & 22.10 & 8.63 & 309.36 & 9.08 & 12.16 & 28.04 & 4.051 \\
$\mathrm{PbS}(\mathrm{Te})$ & 0 & 108.92 & 11.75 & 16.08 & 132.84 & 10.62 & 11.37 & 44.51 & 4.625 \\
& 50 & 103.54 & 10.92 & 15.43 & 132.01 & 10.03 & 11.90 & 41.62 & 4.547 \\
& 100 & 99.06 & 10.01 & 13.37 & 129.33 & 9.97 & 11.25 & 38.04 & 3.932 \\
$\mathrm{~Pb}(\mathrm{Sn}) \mathrm{S}(\mathrm{Te})$ & 0 & 116.71 & 37.63 & 9.72 & 113.42 & 7.69 & 8.99 & 39.70 & 3.115 \\
& 50 & 114.65 & 35.87 & 8.82 & 113.54 & 7.57 & 8.91 & 33.14 & 3.69 \\
& 100 & 111.23 & 34.31 & 8.17 & 111.89 & 7.44 & 8.37 & & 3.69 \\
\hline \hline
\end{tabular}

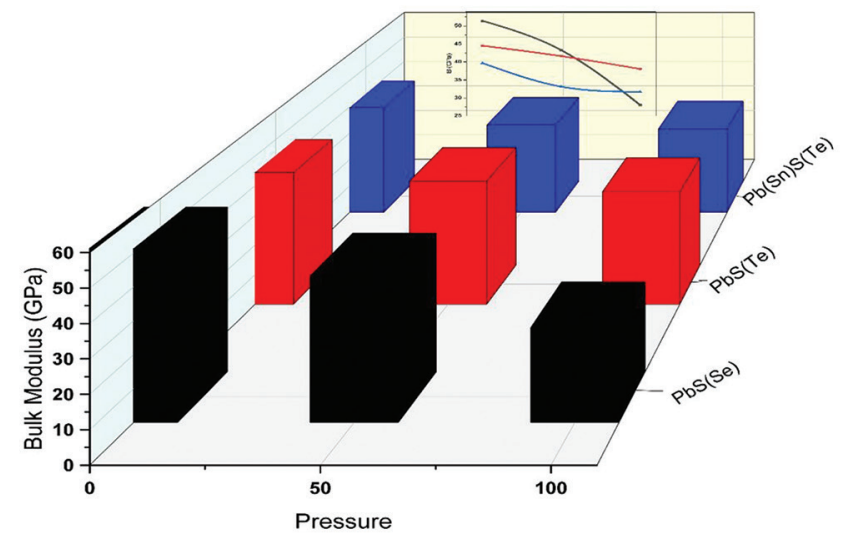

Fig. 3. Bulk modulus of the various pressures ternary and quaternary alloys.

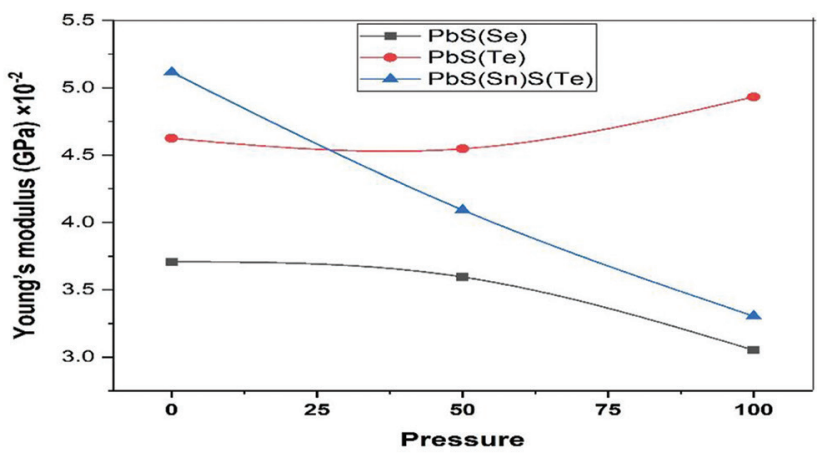

Fig. 4. Young's modulus of the ternary and quaternary alloys under various pressures.

$\mathrm{Pb}_{\mathrm{x}} \mathrm{Sn}_{1-\mathrm{x}} \mathrm{S}_{\mathrm{y}} \mathrm{Te}_{1-\mathrm{y}}$ quaternary alloys. The elastic parameters $C_{i j}$ play a significant role in some mechanical performances of the alloys, particularly in special application conditions including as internal strain and stress. Fig. 2 illustrates the findings of $C i j$ of $\mathrm{PbS}_{\mathrm{x}} \mathrm{Se}_{1-\mathrm{x}}$ and $\mathrm{PbSxTe}_{1-\mathrm{x}}$ ternary and $\mathrm{Pb}_{\mathrm{x}} \mathrm{Sn}_{1-}$. ${ }_{x} \mathrm{~S}_{\mathrm{y}} \mathrm{Te}_{1-\mathrm{y}}$ quaternary alloys for $\mathrm{x}$ and $\mathrm{y}=0.5$ compositions as a change of pressure from 0, 50, and $100 \mathrm{kbar}$. Experimental data for these alloys do not exist. Table II gives an explanation of that $C_{11}, C_{12}$, and $C_{44}$ decrease as pressure increases. On the other side, $C_{33}, C_{44}$ and $C_{66}$ decrease whereas pressure increases with different rates.

As it can be seen in Table II, the variations of bulk and young modulus of $\mathrm{PbS}_{\mathrm{x}} \mathrm{Se}_{1-\mathrm{x}}$ and $\mathrm{PbS}_{\mathrm{x}} \mathrm{Te}_{1-\mathrm{x}}$ ternary and $\mathrm{Pb}_{\mathrm{x}} \mathrm{Sn}_{1-}$
${ }_{\mathrm{x}} \mathrm{S}_{\mathrm{y}} \mathrm{Te}_{1-\mathrm{y}}$ quaternary alloys for $\mathrm{x}$ and $\mathrm{y}=0.5$ as a function of pressure from 0,50 , and $100 \mathrm{kbar}$ are demonstrated in Figs. 3 and 4.

In the final analysis, whereas the pressure rises, the parameters vary regularly. It displays that the varying of bulk modulus with pressure of $\mathrm{PbS}_{\mathrm{x}} \mathrm{Se}_{1-\mathrm{x}}$ alloys decreases quickly and the varying of bulk modulus for $\mathrm{PbSxTe}_{1-\mathrm{x}}$ alloys decreases gradually with the pressure. As can be noted in Fig. 3, quaternary alloys of $\mathrm{Pb}_{\mathrm{x}} \mathrm{Sn}_{1-\mathrm{x}} \mathrm{S}_{\mathrm{y}} \mathrm{Te}_{1-\mathrm{y}}$ bulk modulus decrease regularly. It can be indicated as one of the key references for the other works in the future. In Fig. 4, the young modulus parameters decline, as pressure goes up, but the varying of bulk modulus rises with the pressure in $\mathrm{PbSxTe}_{1-\mathrm{x}}$ alloys.

\section{CONCLUSIONS}

The current study indicates the mechanical performance of $\mathrm{PbS}_{\mathrm{x}} \mathrm{Se}_{1-\mathrm{x}}$ and $\mathrm{PbS}_{\mathrm{x}} \mathrm{Te}_{1-\mathrm{x}}$ ternary and $\mathrm{Pb}_{\mathrm{x}} \mathrm{Sn}_{1-\mathrm{x}} \mathrm{S}_{\mathrm{y}} \mathrm{Te}_{1-\mathrm{y}}$ quaternary alloys for $\mathrm{x}$ and $\mathrm{y}=0.5$ as a function of the pressure from 0 , 50, and 100 kbar using DFT. The first principles method is used to achieve the results depending on the LDA using plane wave pseudopotentials. The traditional mechanical stability conditions for these ternary and quaternary mixed crystals are satisfied by the elastic parameters. The pressure increasing leads to a decrease in the lattice parameters. Moreover, parameter bulk and young modulus go down with pressure increasing, but young modulus parameters of $\mathrm{PbS}_{\mathrm{x}} \mathrm{Te}_{1-\mathrm{x}}$ ternary go up by pressure. The results display the calculation of $C i j$ of all alloys as a pressure from 0,50 , and 100 kbar. Pressure increasing progress to decrease in $C_{11}, C_{12}$, and $C_{44}$ and in $C_{33}, \mathrm{C}_{44}$, and $C_{66}$ in separate rates. The data of the current study include $P=50$ and $100 \mathrm{kbar}$, and it can be emphasized on in the future studies.

\section{REFERENCES}

Ahmed, R., Hashemifar S.J. and Akbarzadeh, H., 2008. First-principles study of the structural and electronic properties of III-phosphides. Physica B: Condensed Matter, 403(10-11), pp.1876-1881.

Dar, S.A., Srivastava, V., Sakalle, U.K., Parey, V. and Pagare, G., 2017. DFT investigation on electronic, magnetic, mechanical and thermodynamic properties under pressure of some EuMO3 $(\mathrm{M}=\mathrm{Ga}$, In) perovskites. Materials Research Express, 4(10), p. 11.

Gopal, P., Fornari, M., Curtarolo, S., Agapito, L.A., Liyanage, L.S.I. and Nardelli, M.B., 2015. Improved predictions of the physical properties of Zn-and 
Cd-based wide band-gap semiconductors: A validation of the ACBN0 functional. Physical Review B-Condensed Matter and Materials Physics, 91(24), pp.1-9.

Hutter, J. Iannuzzi, M., Schiffmann, F. and VandeVondele, J., 2014. Cp2k: Atomistic simulations of condensed matter systems. Wiley Interdisciplinary Reviews: Computational Molecular Science, 4(1), pp.15-25.

Jandow, N.N., Othman, M., Habubi, N.F. and Chiad, S.S., 2019. Theoretical and experimental investigation of structural and optical properties of lithium doped cadmium oxide thin films. Materials Research Express, 6(11), p.116434.

Kacimi, S. Zaoui, A., Abbar, B. and Bouhafs, B., 2008. Ab initio study of cubic PbSxSe1-x alloys. Journal of Alloys and Compounds, 462(1-2), pp.135-141.

Koch, C.C., Youssef, K. M., Scattergood, R. O. and Murty, K. L., 2005. Breakthroughs in optimization of mechanical properties of nanostructured metals and alloys. Advanced Engineering Materials, 7(9), pp.787-794.

Labidi, M. Meradji, H., Sebti, G. and Labidi, S., 2011. Structural, electronic, optical and thermodynamic properties of $\mathrm{PbS}, \mathrm{Pbse}$ and their ternary alloy pbs1xsex. Modern Physics Letters B, 25(7), pp.473-486.

Lebedev, A. and Sluchinskaya, I., 1994. Ferroelectric phase transitions in iv-vi semiconductors associated with off-center ions. Ferroelectrics, 157(1), pp. $275-280$.

McCann, P.J., 2006. IV-VI semiconductors for mid-infrared optoelectronic devices. In: Mid-infrared Semiconductor Optoelectronics. Springer, London, pp.237-264.

McGinty, R.K., Köhn, M., Chatterjee, C., Chiang, K.P., Pratt, M.R. and Muir, T.W., 2009. Structure-activity analysis of semisynthetic nucleosomes: Mechanistic insights into the stimulation of Dot1L by ubiquitylated histone H2B. ACS Chemical Biology, 4(11), pp.958-968.

Milman, V., Refson, K., Clark, S.J., Pickard, C.J., Yates, J.R., Gao, S.P., Hasnip, P.J., Probert, M., Perlov, A. and Segall, A., 2010. Electron and vibrational spectroscopies using DFT, plane waves and pseudopotentials: CASTEP implementation. Journal of Molecular Structure: THEOCHEM, 954(1-3), pp.22-35.

Mouhat, F. and Coudert, F.X., 2014. Necessary and sufficient elastic stability conditions in various crystal systems. Physical Review B-Condensed Matter and Materials Physics, 90(22), pp.4-7.
Othman, M., Kasap, E. and Korozlu, N., 2010a. Ab-initio investigation of structural, electronic and optical properties of InxGa1-xAs, GaAs1-yPy ternary and InxGa1-xAs1-yPy quaternary semiconductor alloys. Journal of Alloys and Compounds, 496(1-2), pp.226-233.

Othman, M., Kasap, E. and Korozlu, N., 2010b. The structural, electronic and optical properties of In $<$ inf $>\mathrm{x}</$ inf $>\mathrm{Ga}<\mathrm{inf}>1-\mathrm{x}</ \mathrm{inf}>\mathrm{P}$ alloys. Physica $B$ : Condensed Matter, 405(10), pp.991-1005.

Othman, M., Salih, S., Sedighi, M. and Kasapd, K., 2019. Impact of pressure and composition on the mechanical behavior of InxGa1-xAs1-yPy and AlxIn1xSb1-yPy quaternary alloys. Results in Physics, 14, p.5.

Othman, M.S., 2013. Simulation mechanical properties of lead sulfur selenium under pressure. Journal of Modern Physics, 4(2), pp.185-190.

Othman, M.S., 2016. Theoretical analysis of linear optical properties of $\mathrm{PbS} \mathrm{x}$ Se 1-x $(\mathrm{X}=0.5)$. Journal of Kerbala University, 14(2), pp.221-228.

Othman, M.S., Mishjil, K.A. and Habubi, N.F., 2012. Structural and optical properties of GaAs $0.5 \mathrm{Sb} 0.5$ and In $0.5 \mathrm{Ga} 0.5 \mathrm{As} 0.5 \mathrm{Sb} 0.5$ : Ab initio calculations for pure and doped materials. Chinese Physics Letters, 29(3), p.037302.

Sanati, M., Albers, R.C., Lookman, T. and Saxena, A., 2013. First-order versus second-order phase transformation in AuZn. Physical Review B-Condensed Matter and Materials Physics, 88(2), pp.1-10.

Sedighi, M., Nia, B.A., Hamada, A.H., Othmana, M.S., 2020. Electronic and optical properties of SrS nanosheet in 001 and 101 directions. Computational Condensed Matter, 22, p.e00445.

Segall, M.D., Lindan, P.J., Probert, M.J., Pickard, C.J., Hasnip, P.J., Clark, S.J. and Payne, M.C., 2002. First-principles simulation: Ideas, illustrations and the CASTEP code. Journal of Physics Condensed Matter, 14(11), pp.2717-2744.

Suresh Babu, K., Vijayan, C. and Devanathan, R., 2004. Strong quantum confinement effects in polymer-based $\mathrm{PbS}$ nanostructures prepared by ionexchange method. Materials Letters, 58(7-8), pp.1223-1226.

Weyand, S., 2007. Purification, Crystallisation and X-ray Structure Analysis of Proteins From the Lysine Biosynthetic Pathway of Mycobacterium Tuberculosis and Structural Studies of Membrane Proteins from Deinococcus Radiodurans R1 and Escherichia coli K12'. University of Konstanz, Konstanz. 